\title{
Walnut Trim down Lipid Profile and BMI in Obese Male in Different Ethnic Groups of Quetta Population, Pakistan
}

\author{
Rehana Mushtaq ${ }^{1}$, Rubina Mushtaq ${ }^{1}$, Sobia Khwaja ${ }^{1}$, Zahida Tasawar Khan ${ }^{2}$ \\ ${ }^{1}$ Federal Urdu University of Arts, Science \& Technology, Gulshan Iqbal Campus, Karachi, Pakistan; ${ }^{2}$ Institute of Pure and Applied \\ Biological Sciences, Bahauddin Zakriya University, Multan, Pakistan. \\ Email: gr8_dezirez@hotmail.com,mushtaqrehana@ymail.com
}

Received June $4^{\text {th }}, 2013$; revised July $4^{\text {th }}, 2013$; accepted July $11^{\text {th }}, 2013$

Copyright (C) 2013 Rehana Mushtaq et al. This is an open access article distributed under the Creative Commons Attribution License, which permits unrestricted use, distribution, and reproduction in any medium, provided the original work is properly cited.

\begin{abstract}
A total of 64 male obese subjects were randomized to observe the effect of $40 \mathrm{~g}$ of walnut in daily breakfast on lipid profile and Body Mass Index (BMI), total Cholesterol (CHO), Triglyceride (TG) High Density Lipoprotein (HDL) cholesterol and Low Density Lipoprotein (LDL) cholesterol in obese male subjects of various ethnics i.e. Baloch (B), Pathan (P), Hazara (H) and Punjabi (PU) residing in Quetta region of Balochistan for this purpose four weeks controlled study was designed. A batch of 32 obese male subjects 8 from each ethnic group as a control and another batch of 32 obese males 8 from each ethnic group as treated were selected. Twelve hour fasting blood samples a day after stoppage of walnut were taken from obese control and obese treated subjects. Daily walnut consumption in obese male subjects evidently demonstrated reduced BMI in all ethnic groups. Walnut supplementation in obese exhibited significant reduction in cholesterol level in Baloch $(\mathrm{P}<0.001)$ and Punjabi $(\mathrm{P}<0.01)$ males. There was profound and statistically significant $[\mathrm{B}(\mathrm{P}<0.05), \mathrm{P}(\mathrm{P}<0.05), \mathrm{H}(\mathrm{P}<0.01)$ and $\mathrm{PU}(\mathrm{P}<0.05)]$ elevation in HDL-C in all male ethnic groups. In male sub-population LDL-C was significantly $[\mathrm{P}(\mathrm{P}<0.01), \mathrm{H}(\mathrm{P}<0.001)$ and $\mathrm{PU}(\mathrm{P}<0.05)]$ reduced in these groups. In these subjects walnut supplementation showed pronounced reduction $[\mathrm{B}(\mathrm{P}<0.001), \mathrm{P}(\mathrm{P}<0.05), \mathrm{H}(\mathrm{P}<0.001)$ and PU $(\mathrm{P}<0.001)]$ in triglyceride levels. The constructive influence of walnut on lipid profile suggests that walnut rich diet may have advantageous effects beyond changes in plasma lipid level.
\end{abstract}

Keywords: Walnut; Cholesterol; Triglyceride; High Density Lipoprotein; Low Density Lipoprotein

\section{Introduction}

Obesity and Overweight are a global health problem [1, $2]$. It is related with a number of acute diseases and lipoprotein disorder which is fears of possible weight gain. Obesity outcomes from a continuous left over of energy intake contrast to energy disbursement, which escort to storage of unnecessary amounts of triglycerides in adipose tissue [3]. In the US, the recent incidence of plumpness among adults is about 33\% [4] similarly in the United Kingdom obesity rate has increased to about 23\% [5] and these incidence statistics are reflected all over the rest world [6-8]. Obesity is now documented as an epidemic [9] and in spite of present intensive efforts to decrease obesity via diet, exercise, education, surgery and medicinetherapies; an effective long term solution to this pandemic is yet to be provided. Obesity, overweight, family history of diabetes mellitus, and hypertension are main factors of type 2 diabetes in Pakistan [10]. Rate of obesity increase in every age, sex, race, and smoking status, and data shows that divisions of persons in the highest weight category (i.e., BMI $>40 \mathrm{~kg} / \mathrm{m}$ ) have increased more than those in lower BMI category (BMI < $35 \mathrm{~kg} / \mathrm{m})[11]$.

It has been reported that blood pressure in youth, serum lipid levels, and body mass index (BMI) strongly associated with middle age [12].

Obese people tend to have relatively high triglyceride (TG), low HDL-C and increased LDL-C. Hyperglycemia prevails despite high levels of insulin referred as hyperinsulinemia. These all constitute major factors in the pathogenesis of Cardiac Heart Disease. The recent investigations indicate that these parameters are essential in study of characteristics of obesity. Branchi has studied serum lipids in patients of metabolic syndrome while subjecting them meals of different composition [13].

Plasma cholesterol levels are fairly reduced when low cholesterol diets are used [14]. The result of dietary cholesterol on plasma cholesterol levels may be predisposed 
by the types of fatty acid consumed which may be saturated or unsaturated [15].

Long term nut consumption is associated with lower body weight and lower risk of obesity also high light by Sabate [16]. Further these findings are support and recommended by Bes-Rastrollo [17] that nut consumption is an important component of a cardio protective diet and those participants who fulfill risk factors for obesity and they ate nuts two or more times per day had a significantly lower risk of also allay fears of possible weight gain.

Nuts have unique composition i.e. vitamins, minerals, mono- and polyunsaturated fatty acids, fiber, arotenoids, phenols (particularly flavonoids), phytosterols, squalene and tocopherols which slowing the pathogenesis of chronic disease, antioxidant and anti-inflammatory activity as well as the capacity to promote detoxification, reduce cell proliferation, and/or lower serum low-density lipoprotein (LDL) cholesterol [18]. Nuts are main element of healthy diets such as the Mediterranean diet. Outcome of several epidemiological studies and mores suggest that there may be an association between frequent nut consumption and a reduced rate of CHD [19].

There was substantiation of decreased total cholesterol and LDL cholesterol in diets of at-risk subjects supplemented with two to three servings of walnuts per day, with no net gain in body weight [20]. Lipid profile of patients with type 2 diabetes improved after including 30 g walnuts/day [21]. The previous findings show [22,23] that the average American diet, both the LA and the ALA diets including walnuts lowered total cholesterol $11 \%$, LDLs $11 \%-12 \%$ and triglycerides $18 \%$.

The population of city of Quetta and some other towns in Balochistan well represent different ethnic groups of [Pathan (P), Baloch (B), Hazara (H) and Punjabi (PU)]. Thus a study on the basis of ethnicity was possible in such populations.

The region of Quetta city which is situated in North West of Pakistan is inhibited by various ethnic groups since many decade and present at high altitude of 1600 meter.

Thus, with the above concept of interactive mechanism the present study was planned to investigate the effect of dietary lipids supplementation on lipid profile and BMI in obese male. In order to investigate this point, walnuts were incorporated into the diets fed to male obese subjects that provided.

\section{Materials and Methods}

The study was designed as intervention-controlled clinical pattern trials with participant volunteers were selected from the local community, primarily through pasting posters in hospitals, universities, colleges. Newspaper advertisements, telephonic messages, emails and by coun- seling in different communities study was carried out in selected ethnic groups [Pathan (P), Baloch (B), Hazara (H) and Punjabi (PU)] in Quetta, Balochistan participant and also in various medical camps.

Volunteers were screened and those were barred from the trial that had known nut allergies, consumed nuts frequently, smoked cigarettes and had history of atherosclerotic or hypertension or metabolic disorder. Discussions with the selected volunteers were carried out to explain the protocol of the study. Thirty two male obese subjects (experimental) 8 from each ethnic group, participated in the study, and thirty two control male obese subjects were selected. Assortment of the subjects were according to the WHO, 1998 criteria where BMI $=30$ 34.9 is considered as obese I (at a moderate risk of comorbidities), $\mathrm{BMI}=35-39.9$ is obese II (at a severe risk of co-morbidities), and BMI $\geq 40$ is obese III (at a very severe risk of co morbidities).

The control volunteers were asked to give $12 \mathrm{hrs}$ fasting blood sample, at the start of the study and only experimentally selected subjects were ask to take daily $40 \mathrm{~g}$ walnut in their breakfast along with normal eating habits for four weeks. At the end of the fourth week they were sampled for blood after a $12 \mathrm{~h}$ fast and general data was collected. BMI in the general observations and blood samples before and after the walnut consumption were subjected for estimation of total cholesterol, triglycerides, HDL cholesterol and LDL cholesterol with commercial kits.

Statistical analysis was undertaken with statistical program of Sigma Stat 3.5. Student $t$ test was used for comparison between normal and obese subject groups and $\mathrm{P}$ $<0.05$ was considered as statistically significant.

\section{Results}

\subsection{Ages}

The age of the control obese subjects ranged between $37.9 \pm 2.7,43.6 \pm 5.2,44.5 \pm 4.3$ and $41.1 \pm 3.7$ years and in walnut supplemented batch of obese male subjects it was ranging at $41.9 \pm 3.0,45.1 \pm 4.9,44.1 \pm 3.5$ and $43.8 \pm 3.4$ years in Baloch, Pathan, Hazara and Punjabi sub-populations respectively. The subjects were in close range of age and well-matched for the comparison.

\subsection{Body Mass Index (BMI)}

The body mass index of obese Baloch was $40.9 \pm 1.4$ $\mathrm{kg} / \mathrm{m}^{2}$ and $40.6 \pm 0.5 \mathrm{~kg} / \mathrm{m}^{2}$ in control and walnut supplemented obese subjects respectively. The average value of BMI were $40.6 \pm 1.3 \mathrm{~kg} / \mathrm{m}^{2}$ in control Pathan volunteers and $39.6 \pm 0.7 \mathrm{~kg} / \mathrm{m}^{2}$ in walnut taking volunteers. In Hazara the mean values of BMI were $40.9 \pm 1.3 \mathrm{~kg} / \mathrm{m}^{2}$ in controls while it was $38.5 \pm 0.6 \mathrm{~kg} / \mathrm{m}^{2}$ in walnut supplemented groups. In Punjabi control volunteers the BMI was $41.3 \pm 1.2 \mathrm{~kg} / \mathrm{m}^{2}$ and in walnut consumers it was 


\section{$39.6 \pm 1.0 \mathrm{~kg} / \mathrm{m}^{2}$ (Table 1).}

Body mass index in walnut supplemented obese subjects was found to be lower in all ethnic sub population in comparison to controls obese, however, non significant finding were experienced in all ethnic group. It is quite obvious from these results that walnut intakes had no effect on BMI.

\subsection{Total Cholesterol}

In Baloch control obese volunteers of this batch the cholesterol concentration was $268.6 \pm 4.8 \mathrm{mg} / \mathrm{dl}$. Walnut supplemented subjects $(239.8 \pm 3.7 \mathrm{mg} / \mathrm{dl})$ manifested remarkable and statistically significant $(\mathrm{P}<0.001)$ reduction of $10.8 \%$ in walnut taking subjects. The cholesterol concentration in control Pathan subjects of this ethnicity level observed to be $261.9 \pm 4.0 \mathrm{mg} / \mathrm{dl}$, comparably in walnut supplemented volunteers it was $256.6 \pm 2.5$ $\mathrm{mg} / \mathrm{dl}$. The minor reduction of only $2.2 \%$ was noticed. An average total cholesterol fraction of $251.3 \pm 4.4 \mathrm{mg} / \mathrm{dl}$ and $245.1 \pm 3.6 \mathrm{mg} / \mathrm{dl}$ was estimated in controls of obese Hazara volunteers and walnut taking Hazara subjects respectively. Walnut supplementation did not bring any significant change. Obese Punjabi volunteers exhibited a concentration of $259.9 \pm 3.6 \mathrm{mg} / \mathrm{dl}$ and $243.4 \pm 3.0 \mathrm{mg} / \mathrm{dl}$ total cholesterol in controls and walnut taking respectively. The fraction was statistically significant $(\mathrm{P}<$ 0.004 ) lower with $6.4 \%$ in walnut supplemented subjects (Figure 1).

Although the cholesterol concentration estimated was beyond the normal range in walnut treated subjects, but it demonstrated beneficial effects in Baloch and Punjabi volunteers compare to controls.

\subsection{Low Density Lipoprotein Cholesterol}

The overall LDL cholesterol response is presented in Figure 2 in male subjects experiment.

In Baloch obese control male subjects average value of LDL cholesterol concentration was $191.8 \pm 2.1 \mathrm{mg} / \mathrm{dl}$ and in walnut supplemented it was $188.9 \pm 1.3 \mathrm{mg} / \mathrm{dl}$. The difference was non significant with minor reduction of only $1.6 \%$. A concentration of $191.6 \mathrm{mg} / \mathrm{dl}$ and 175.8

Table 1. Average ages and BMI $\mathrm{kg} / \mathrm{m}^{2}$ in obese male population of all ethnic groups in controls and with walnut supplementation. Con: control obese; Walnut S: walnut supplementation.

\begin{tabular}{ccccc}
\hline $\begin{array}{c}\text { Ethic } \\
\text { Groups }\end{array}$ & $\begin{array}{c}\text { Age } \\
\text { (Con) }\end{array}$ & $\begin{array}{c}\text { Age } \\
\text { (Walnut S) }\end{array}$ & $\begin{array}{c}\text { BMI kg/m } \\
\text { (Con) }\end{array}$ & $\begin{array}{c}\text { BMI kg/m } \\
\text { (Walnut S ) }\end{array}$ \\
\hline Baloch & $37.9 \pm 2.7$ & $41.9 \pm 3.0$ & $40.9 \pm 1.4$ & $40.6 \pm 0.5$ \\
Pathan & $43.6 \pm 5.2$ & $45.1 \pm 4.9$ & $40.6 \pm 1.3$ & $39.6 \pm 0.7$ \\
Hazara & $44.5 \pm 4.3$ & $44.1 \pm .3 .5$ & $40.9 \pm 1.3$ & $38.5 \pm 0.6$ \\
Punjabi & $41.1 \pm 3.7$ & $43.8 \pm 3.4$ & $41.3 \pm 1.2$ & $39.6 \pm 1.0$ \\
\hline
\end{tabular}

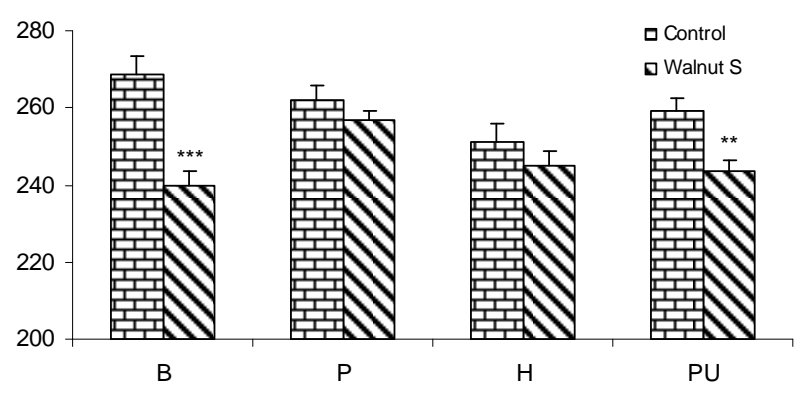

Figure 1. Serum total cholesterol $\mathrm{mg} / \mathrm{dl}$ in obese $\mathrm{M}$ (males), of controls and walnut supplementation (S) in B (Baloch), $P$ (Pathan), H (Hazara) and PU (Punjabi) ethnic groups. ${ }^{* *} \mathrm{P}<$ 0.01, ${ }^{* * *} \mathbf{P}<0.001$.

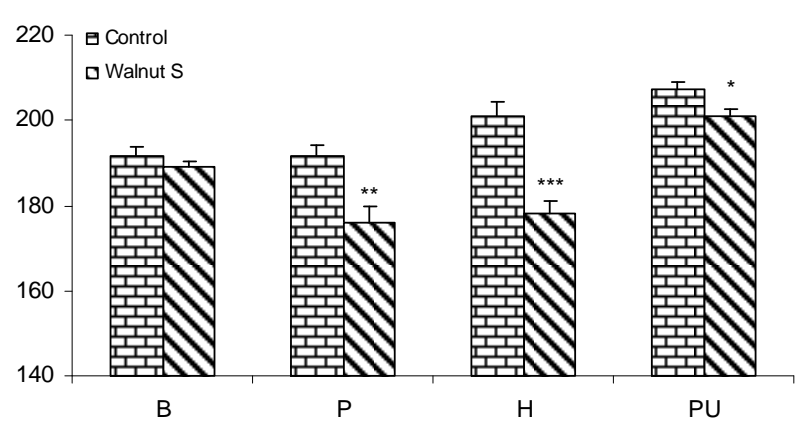

Figure 2. Serum LDL cholesterol $\mathrm{mg} / \mathrm{dl}$ in obese $\mathrm{M}$ (males), of controls and walnut supplementation (S) in B (Baloch), $P$ (Pathan), H (Hazara) and PU (Punjabi) ethnic groups. * $\mathbf{P}<$ $0.05,{ }^{* *} \mathbf{P}<0.01,{ }^{* * *} \mathbf{P}<0.001$.

$\pm 4.0 \mathrm{mg} / \mathrm{dl} \mathrm{LDL}$ cholesterol was estimated in the controls and in walnut supplemented Pathan volunteers respectively. The noticeable and highly significant $(\mathrm{P}<$ $0.01)$ reduction was determined in walnut taking obese volunteers with value of $8.3 \%$. Obese Hazara control volunteers showed an average value of $201.1 \pm 3.1 \mathrm{mg} / \mathrm{dl}$ LDL cholesterol and it was $178.1 \pm 3.1 \mathrm{mg} / \mathrm{dl}$ in walnut consuming Hazara subjects. Approximately $21.5 \%$ lower LDL cholesterol concentration was estimated in walnut supplemented group which was highly significant $(\mathrm{P}<$ 0.001). In Punjabi volunteers of this group the concentration of LDL cholesterol was $207.3 \pm 1.9$ in the controls and was $201.1 \pm 1.5 \mathrm{mg} / \mathrm{dl}$ in walnut consuming subjects. The walnut supplementation showed marked and statistically significant $(\mathrm{P}<0.025)$ reduction of $3 \%$ (Figure 2).

A significant response of reduction in LDL cholesterol concentration had been noticed in walnut supplemented subjects in all ethnic sub population except in Baloch where minor decline noticed.

\subsection{High Density Lipoprotein}

The Figure 3 presents the overview of the HDL cholesterol response in the male subjects of the trials.

In Baloch control obese male subjects the concentra- 


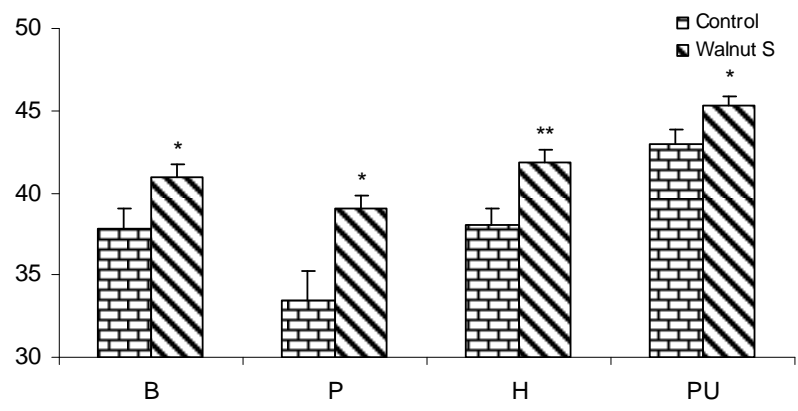

Figure 3. Serum HDL cholesterol $\mathrm{mg} / \mathrm{dl}$ in obese males, of controls and walnut supplementation (S) in B (Baloch), $P$ (Pathan), H (Hazara) and PU (Punjabi) ethnic groups. ${ }^{*} \mathbf{P}<$ $0.05,{ }^{* *} \mathbf{P}<0.01$.

tion of HDL cholesterol is $37.8 \pm 1.2 \mathrm{mg} / \mathrm{dl}$ comparably in walnut taking subjects of this ethnicity the level was observed to be $41 \pm 0.7 \mathrm{mg} / \mathrm{dl}$. Walnut supplemented subjects exhibited considerable and significant $8.4 \%(\mathrm{P}<$ 0.037 ) increase in HDL. A concentration of $33.5 \pm 1.8$ $\mathrm{mg} / \mathrm{dl}$ HDL cholesterol was estimated in obese Pathan controls and $39.1 \pm 0.7 \mathrm{mg} / \mathrm{dl}$ in walnut consumers. Comparison of two group showed noticeable and significant increase of $16.7 \%(\mathrm{P}<0.011)$ in HDL cholesterol. Obese Hazara volunteers of this group exhibited the concentration of cholesterol at $38.0 \pm 1.0 \mathrm{mg} / \mathrm{dl}$ in the controls and $41.8 \pm 0.8 \mathrm{mg} / \mathrm{dl}$ in walnut taking subjects. The walnut consumers group manifested statistically significant elevation of $10 \%(\mathrm{P}<0.008)$. An average value of the fraction at $43.1 \pm 0.8 \mathrm{mg} / \mathrm{dl}$ in the controls and $45.3 \pm 0.6 \mathrm{mg} / \mathrm{dl}$ in walnut supplemented Punjabi subjects was observed. The fraction was increased 5\% in walnut supplemented subjects and was statistically significant $(\mathrm{P}<0.045)$ (Figure 3). In the obese males of the entire ethnic sub populations the HDL cholesterol concentration estimated in controls were in unhealthy range, however after walnut supplementation it exhibited a good response in all ethnic groups, although in Punjabi subjects it was already in healthy range, even than a significant raise was observed.

\subsection{Triglycerides}

In Baloch obese male volunteers the concentration of triglycerides was $222.8 \pm 3.2 \mathrm{mg} / \mathrm{dl}$ while it was $201.8 \pm$ $1.9 \mathrm{mg} / \mathrm{dl}$ in walnut supplemented subjects. The fraction is found to be appreciably $9.5 \%$ lowered in walnut supplemented subjects than controls and was significant statistically $(\mathrm{P}<0.001)$. Triglyceride concentration of 227.5 $\pm 2.9 \mathrm{mg} / \mathrm{dl}$ and $218.1 \pm 2.5 \mathrm{mg} / \mathrm{dl}$ was estimated in the obese controls and obese walnut consumers Pathan volunteers. Walnut supplementation caused marked lowering of $11.3 \%$ in $\mathrm{Tg}$ fraction was significant statistically $(\mathrm{P}<0.028)$. In Hazara volunteers of this group the concentration of triglycerides was $220.1 \pm 2.2 \mathrm{mg} / \mathrm{dl}$ in con- trols and $196.8 \pm 2.5 \mathrm{mg} / \mathrm{dl}$ in walnut supplemented Hazara subjects. The fraction was found to be markedly lower $10.6 \%$ in the walnut taking subjects and was significant statistically $(\mathrm{P}<0.001)$. An average fraction was at $219.8 \pm 2.6 \mathrm{mg} / \mathrm{dl}$ in the control and $195.5 \pm 2.8 \mathrm{mg} / \mathrm{dl}$ in walnuts supplemented Punjabi subjects. Walnut supplementation caused noticeable effects on Tg concentration with decreased levels and statistically significant ( $\mathrm{P}$ $<0.001)$ (Figure 4).

Walnut manifested its beneficial effects on triglyceride concentration on obese males of all ethnic sub population the supplementation exhibited significant lowering characteristics comparable to controls.

\section{Discussion}

Walnut is an inexpensive and safe treatment, which significantly reduces lipid profile and raises HDL-c. These effects perhaps are due to the reduction of SREBP-1c expression and the rise of PPAR $\alpha$ expression in diabetic rat [24].

Overweight and obesity lead to serious health consequences, with the risk increasing progressively with body mass index (BMI) and consequently risk of heart disease, type 2 diabetes and some cancers like endometrial, breast and colon cancer [25]. Swiftly increasing obesity incidence rates require weight management to be precedence for the anticipation and cure of chronic diseases. Nutrition supplementation and enhanced activity have been the notable approaches in this regard and numerous studies have been appearing on these aspects. In the present study walnut supplementations effects have been investigated in obese male volunteers of the ethnic sub-populations.

The results of present study clearly have demonstrated that daily walnut consumption in obese male subjects reduced BMI in all ethnic groups. In all other studied sub-population non significant lowering was noticed in BMI. These findings agree with the previous result [26] and associated with a slightly lower risk of obesity.

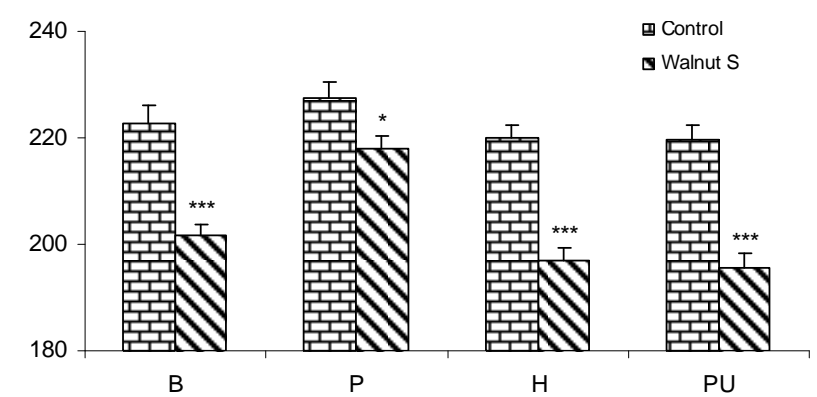

Figure 4. Serum triglyceride $\mathrm{mg} / \mathrm{dl}$ in obese $M$ (males), of controls and walnut supplementation (S) in B (Baloch), $P$ (Pathan), H (Hazara) and PU (Punjabi) ethnic groups. ${ }^{*} \mathbf{P}<$ $0.05,{ }^{* * *} \mathbf{P}<0.001$. 
A randomized controlled experiment of a moderate fat, low-energy diet compared with a low fat, low-energy diet for weight loss in overweight adults. Participants following a Mediterranean-style moderate fat weight loss diet, including peanuts and tree nuts like walnuts were able to improve weight loss and keep weight off for a longer period than people following the usually suggested low fat diet. The previous studies suggest that the diet sensation of the partakers may have been ascribed to the satiety of the tree nuts (i.e. walnuts) a key factor in weight loss [27].

Two reviews summarize the findings of 15 human intervention trials that evaluated the effects of nut consumption on body weight changes and concluded that self-selected diets that included nuts in free-living populations did not have a tendency to increase body weight [28,29].

Higher phospholipid proportions of oleic, alpha-linolenic (ALA), and docosahexaenoic acids showed inverse associations to carotid artery thickness in subjects with primary dyslipidemia. The researchers concluded that high intakes of specific unsaturated fatty acids might explain, in part, the low incident of IHD in the Spanish population [30].

The results of present study demonstrated that in obese subjects, walnut in take exhibits significant reduction in cholesterol level in Baloch $(\mathrm{P}<0.001)$ and Punjabi $(\mathrm{P}<$ $0.01)$ males. Walnut consumption exhibited profound and statistically significant $[\mathrm{B}(\mathrm{P}<0.001), \mathrm{P}(\mathrm{P}<0.05), \mathrm{H}$ $(\mathrm{P}<0.01)$ and $\mathrm{PU}(\mathrm{P}<0.05)]$ reduction of triglyceride in all male ethnic groups. There was profound and statistically significant $[\mathrm{B}(\mathrm{P}<0.05), \mathrm{P}(\mathrm{P}<0.05), \mathrm{H}(\mathrm{P}<0.01)$ and PU $(\mathrm{P}<0.05)$ e elevation in HDL-C in all male ethnic groups.

In male sub-population LDL-C was significantly reduced $[\mathrm{P}(\mathrm{P}<0.01), \mathrm{H}(\mathrm{P}<0.001)$ and $\mathrm{PU}(\mathrm{P}<0.05)]$ in the majority groups. Although it is known that, for every $1 \%$ decrease in plasma LDL cholesterol, there is $2 \%$ reduction in cardiovascular disease (CVD) risk [31]. There are suggestions that walnut-rich diets may have beneficial effects beyond changes in plasma lipid levels. The investigators also concluded that high-walnut-enriched diets considerably reduced total and LDL cholesterol for the period of the short-term experiments. Larger and longer-term tests are needed to address the effects of walnut consumption on cardiovascular risk and body weight [32].

Walnuts are rich in linoleic acid and ALA, which are identified to lower cholesterol when they replace SFA or MUFA in the diet probably by increasing the receptor-mediated uptake of LDL cholesterol [33]. Previous investigation demonstrated that walnut diet significantly reduced total cholesterol and LDL cholesterol [23].

Consumption of walnut has favorable effects on hu- man serum lipid profiles, with a decrease in total and LDL cholesterol as well as triglycerides [34-37] and an increase in HDL cholesterol and apolipoprotein A1 [6].

The findings obtained in the present study further support to the existing recommendations that walnut rich diet may have beneficial effects beyond changes in plasma lipid level.

\section{Conclusion}

Obesity is positively and appreciably associated with BMI and lipid profile, our findings have important public health implications for the management and prevention of obesity related chronic obesity and lipid disorders. Further research aiming at elucidating the temporal relationship between obesity and those diseases is required.

\section{REFERENCES}

[1] World Health Organisation, "Global Strategy on Diet, Physical Activity and Health," 2010. http://www.who.int/dietphysicalactivity/en

[2] T. Lobstein, L. Baur and R. Uauy, "Obesity in Children and Young People: A Crisis in Public Health," Obesity Reviews, Vol. 5, Suppl. 1, 2004, pp. 4-85.

[3] R. Sturm, "Increases in Morbid Obesity in the USA: 2000-2005," Public Health, 2007, Vol. 121, No. 7, pp. 492-496. http://dx.doi.org/10.1016/j.puhe.2007.01.006

[4] C. L. Ogden, S. Z. Yanovski, M. D. Carroll and K. M. Flegal, "The Epidemiology of Obesity," Gastroenterology, 2007, Vol. 132, No. 6, pp. 2087-2102.

http://dx.doi.org/10.1053/j.gastro.2007.03.052

[5] P. G. Kopelman, I. D. Caterson, M. J. Stock and W. H. Dietz, "Clinical Obesity in Adults and Children: In Adults and Children," Blackwell Publishing, Hoboken, 2005, p. 493. http://dx.doi.org/10.1002/9780470987087

[6] F. Lavedrine, D. Zmirou, A. Ravel, F. Balducci and J. Alary, "Blood Cholesterol and Walnut Consumption: A Cross-Sectional Survey in France," Preventive Medicine, Vol. 28, No. 4, 1999, pp. 333-339.

http://dx.doi.org/10.1006/pmed.1999.0460

[7] A. Berghofer, T. Pischon, T. Reinhold, et al., "Obesity Prevalence from a European Perspective: A Systematic Review," BMC Public Health, Vol. 8, 2008, p. 200. http://dx.doi.org/10.1186/1471-2458-8-200

[8] A. D. Sniderman, R. Bhopal, D. Prabhakaran, et al., "Why Might South Asians Be So Susceptible to Central Obesity and Its Atherogenic Consequences? The Adipose Tissue Overflow Hypothesis," International Journal of Epidemiology, Vol. 36, No. 1, 2007, pp. 220-225. http://dx.doi.org/10.1093/ije/dyl245

[9] World Health Organization, "Obesity: Preventing and Managing the Global Epidemic: Report of a WHO Consultation on Obesity," World Health Organization, Geneva, 1998.

[10] J. Zafar, F. Bhatti, N. Akhtar, U. Rasheed, R. Bashir, S. Humayun, A. Waheed, F. Younus, M. Nazar and Umiai- 
mato, "Prevalence and Risk Factors for Diabetes Mellitus in Selected Urban Population of a City in Punjab," Journal Pakistan Medical Association, Vol. 61, No. 1, 2011, pp. 40-47.

[11] S. M. Wright and L. J. Aronne, "Causes of Obesity," Abdom Imaging, Vol. 37, No. 5, 2012, pp. 730-732. http://dx.doi.org/10.1007/s00261-012-9862-x

[12] J. Juhola, C. G. Magnussen, J. S. Viikari, M. Kähönen, N. Hutri-Kähönen, A. Jula, T. Lehtimäki, H. K. Åkerblom, M. Pietikäinen, T. Laitinen, E. Jokinen, L. Taittonen, O. T. Raitakari and M. Juonala, "Tracking of Serum Lipid Levels, Blood Pressure, and Body Mass Index from Childhood to Adulthood: The Cardiovascular Risk in Young Finns Study," Journal of Pediatrics, Vol. 159, No. 4, 2011, pp. 584-590. http://dx.doi.org/10.1016/j.jpeds.2011.03.021

[13] A. Branchi, A. Torri, C. Berra, E. Colombo and D. Sommariva, "Changes in Serum Lipids and Blood Glucose in non Diabetic Patients with Metabolic Syndrome after Mixed Meals of Different Composition," Journal of Nutrition and Metabolism, 2012, Article ID: 215052. http://dx.doi.org/10.1155/2012/215052

[14] P. P. Toth, "High Density Lipoprotein, Cardiovascular Risk," Circulation, Vol. 109, 2004, pp. 1809-1812. http://dx.doi.org/10.1161/01.CIR.0000126889.97626.B8

[15] R. Mcpherson and G. A. Spiller, "Effect of Dietary Fatty Acids and Cholesterol on Cardiovascular Disease Risk Factors in Men," In: G. A. Spiller, Ed., Handbook of Lipids in Human Nutrition, CRC Press, 1996, p. 41.

[16] J. Sabate and Y. Ang, "Nuts and Health Outcomes: New Epidemiologic Evidence," American Journal of Clinical Nutrition, Vol. 89, No. 5, 2009, pp. 1643S-1648S. http://dx.doi.org/10.3945/ajen.2009.26736Q

[17] M. Bes-Rastrollo, J. Sabate, E. Gomez-Gracia, A. Alonso, J. A. Martinez and M. A. Martinez-Gonzalez, "Nut Consumption and Weight Gain in a Mediterranean Cohort: The SUN Study," Obesity (Silver Spring), Vol. 15, No. 1, 2007, pp. 107-116. http://dx.doi.org/10.1038/oby.2007.507

[18] C.-Y. O. Chen and J. B. Blumberg, "Phytochemical Composition of Nuts," Asia Pacific Journal of Clinical Nutrition, Vol. 17, No. 1, 2008, pp. 329-332.

[19] M. Kornsteiner, K. H. Wanger and I. Elmadfa, "Tocopherols and Total Phenolics in 10 Different Nut Types," Food Chemistry, Vol. 98, No. 2, 2006, pp. 381-387. http://dx.doi.org/10.1016/j.foodchem.2005.07.033

[20] E. B. Feldman, "The Scientific Evidence for a Beneficial Health Relationship between Walnuts and Coronary Heart Disease," Journal of Nutrition, Vol. 132, No. 5, 2002, pp. 1062S-1101S.

[21] L. C. Tapsell, L. J. Gillen, C. S. Patch, et al., "Including Walnuts in a Low-Fat/Modified-Fat Diet Substituting Walnuts for Monounsaturated Fat Improves HDL Cholesterol-To-Total Cholesterol Ratios Improves the Serum Lipid Profile of in Patients with Type 2 Diabetes," Diabetes Care, Vol. 27, No. 12, 2000, pp. 2777-2783. http://dx.doi.org/10.2337/diacare.27.12.2777

[22] G. Zhao, T. D. Etherton, K. R. Martin, S. G. West, P. J. Gillies and P. M. Kris-Etherton, "Dietary Alpha-Lino- lenic Acid Reduces Inflammatory and Lipid Cardiovascular Risk Factors in Hypercholesterolemic Men and Women," Journal of Nutrition, Vol. 134, No. 11, 2004, pp. 2991-2997.

[23] E. Ros, I. Núñez, A. Pérez-Heras, M. Serra, R. Gilabert, E. Casals and R. Deulofeu, "A Walnut Diet Improves Endothelial Function in Hypercholesterolemic Subjects: A Randomized Crossover Trial," Circulation, Vol. 109, No. 13, 2004, pp. 1609-1614.

http://dx.doi.org/10.1161/01.CIR.0000124477.91474.FF

[24] A. O. Ebrahim, N. S. Arash and R. Ali, "Effects of Walnut on Lipid Profile as Well as the Expression of SterolRegulatory Element Binding Protein-1c (SREBP-1c) and Peroxisome Proliferator Activated Receptors $\alpha$ (PPAR $\alpha)$ in Diabetic Rat," Food and Nutrition Sciences, Vol. 3, No. 2, 2012, 255-259. http://dx.doi.org/10.4236/fns.2012.32037

[25] World Health Organization, "Obesity: Preventing and Managing the Global Epidemic: Report of a WHO Consultation," WHO Technical Report Series, World Health Organization, Geneva, 2000.

[26] M. Bes-Rastrollo, N. M. Wedick, M. A. Martinez-Gonzalez, T. Y. Li, S. Laura and F. B. Hu, "Prospective Study of Nut Consumption, Long-Term Weight Change and Obesity Risk in Women," American Journal of Clinical Nutrition, Vol. 89, No. 6, 2009, pp. 1913-1919. http://dx.doi.org/10.3945/ajcn.2008.27276

[27] K. McManus, L. Antinoro and F. Sacks, “A Randomized Controlled Trial of a Moderate-Fat, Low Energy Diet Compared with a Low Fat, Low-Energy Diet for Weight Loss in Overweight Adults," International Journal of Obesity, Vol. 25, No. 10, 2001, pp. 1503-1511. http://dx.doi.org/10.1038/sj.ijo.0801796

[28] S. Rajaram and J. Sabate, "Nuts, Body Weight and Insulin Resistance," British Journal of Nutrition, Vol. 96, Suppl. S2, 2006, pp. S79-S86. http://dx.doi.org/10.1017/BJN20061867

[29] P. Garcia-Lorda, I. M. Rangil and J. Salas-Salvado, "Nut Consumption, Body Weight and Insulin Resistance," European Journal of Clinical Nutrition, Vol. 57, Suppl. 1, 2003, pp. S8-S11. http://dx.doi.org/10.1038/sj.ejcn.1601802

[30] A. Sala-Vila, M. Cofán, A. Pérez-Heras, I. Núñez, R. Gilabert, M. Junyent, R. Mateo-Gallego, A. Cenarro, F. Civeira and E. Ros, "Fatty Acids in Serum Phospholipids and Carotid Intima-Media Thickness in Spanish Subjects with Primary Dyslipidemia," American Journal of Clinical Nutrition, Vol. 92, No. 1, 2010, pp. 186-193. http://dx.doi.org/10.3945/ajcn.2009.28807

[31] G. N. Levine, J. F. Keaney, Jr and J. A. Vita, "Cholesterolreduction in Cardiovascular Disease. Clinical Benefits and Possible Mechanisms," New England Journal of Medicine, Vol. 332, No. 8, 1995, pp. 512-521. http://dx.doi.org/10.1056/NEJM199502233320807

[32] D. K. Banel and F. B. Hu, "Effects of Walnut Consumption on Blood Lipids and Other Cardiovascular Risk Factors: A Meta-Analysis and Systematic Review," American Journal of Clinical Nutrition, Vol. 90, No. 1, 2009, pp. 56-63. http://dx.doi.org/10.3945/ajen.2009.27457 
[33] T. A. Mori, V. Burke, I. B. Puddey, G. F. Watts, D. N. O’Neal, J. D. Best and L. J. Beilin, "Purified Eicosapentaenoic and Docosapentaenoic Acids Have Differential Effects on Serum Lipids and Lipoproteins, LDL-C Particle Size, Glucose and Insulin in Mildly Hyperlipidemic Men," American Journal of Clinical Nutrition, Vol. 71, 2000, pp. 1085-1094.

[34] D. Zambón, J. Sabaté, S. Muñoz, et al., "Substituting Walnuts for Monounsaturated Fat Improves the Serum Lipid Profile of Hypercholesterolemic Men and Women. A Randomized Crossover Trial," Annals of Internal Medicine, Vol. 132, No. 7, 2000, pp. 538-546. http://dx.doi.org/10.7326/0003-4819-132-7-200004040-0 $\underline{0005}$

[35] A. Chisholm, J. Mann, M. Skeaff, C. Frampton, W. Suth- erland, A. Duncan and S. Tiszavari, "A Diet Rich in Walnuts Favourably Influences Plasma Fatty Acid Profile in Moderately Hyperlipidaemic Subjects," European Journal of Clinical Nutrition, Vol. 52, No. 1, 1998, pp. 12-16. http://dx.doi.org/10.1038/sj.ejen.1600507

[36] J. Sabate, G. E. Fraser, K. Burke, S. F. Knutsen, H. Bennett and K. D. Lindsted, "Effect of Walnuts on Serum Lipid Levels and Blood Pressure in Normal Men," New England Journal of Medicine, Vol. 238, 1993, pp. 603607. http://dx.doi.org/10.1056/NEJM199303043280902

[37] M. Abbey, M. Noakes, G. B. Belling and P. J. Nestel, "Partial Replacement of Saturated Fatty Acids with almonds or Walnuts Lowers Total Plasma Cholesterol and Low-Density-Lipoprotein Cholesterol," American Journal of Clinical Nutrition, Vol. 59, 1994, pp. 995-999. 